\title{
Supporting Refugee and Immigrant Children: Building Bridges Programme of the International Children's Institute in Canada and Overseas
}

\author{
Ester Cole
}

\begin{abstract}
This article highlights factors concerning refugee school-aged children and their caregivers both in Canada and overseas. This article documents the impact of the International Children's Institute's Building Bridges programme, which has received validation from both qualitative and quantitative studies. It concludes with implications for authentic programmes which combine education, health and NGO (non-governmental organization) sector partnerships.
\end{abstract}

\section{Résumé}

Cest article souligne certains facteurs concernant les enfants réfugiés en âge de scolarité et leurs fournisseurs de soins, au Canada ainsi qu'à l'extérieur. L'article documente l'impact du programme de l'Institut international des enfants, intitulé "Construire des ponts", qui a reçu la validation d'études tant qualitatives que quantitatives. Pour conclure, l'article évoque les implications que cela comporte pour des programmesauthentiques quicombinentdes partenariats entre les secteurs de l'éducation, de la santé et des ONG (organisations non-gouvernementales).

\section{Introduction}

The demographic transformation of communities in Canada and overseas has focused attention on issues related to identification of needs and effective interventions in immigrant and refugee children as well as their families. It has been documented that the number of Canadian immigrants more than doubled

Dr. Ester Cole is a supervising psychologist at the Toronto District School Board and the Chair of The Psychology Foundation of Canada. She has been a senior consultant to The International Children's Institute. The Institute is based in Montreal and Toronto, Canada. in the late 1980s, and in the early 1990s three quarters of immigrant children were of school age. Moreover, of great concern are children who came from war torn countries and those who continue to experience adjustment difficulties during the resettlement phase (United Nations High Commissioner for Refugees 1994; Cole 1998; Vargas 1999; Beiser et al. 1995).

Surveys concerning world refugees often estimate that there are millions of displaced people throughout the world who have resettled or are in the process of applying for resettlement under safer conditions. Their needs for assistance include settlement orientation, shelter, health care, employment, legal representation, second language skills, outreach services, cultural supports and education (Cole 1996). With regard toschool agechildren, it should benoted that migration characteristics are not always disclosed to schools. Thus, factors relating to refugee children's developmental histories including losses, malnutrition, deprivation or gaps in formal education are under-reported by families. This reluctance to reveal information relating to migration status is understandable in view of the vulnerable positions in which many families find themselves. Yet, without knowledge about background circumstances, adequate care and programmes may not be provided by education or mental health services (Ajdukovic \& Ajdukovic 1993; Cole 1998).

Children who have been exposed to aversive events and losses can suffer emotional scars related to trauma. In recent years, for example, attention has been focused on Post-Traumatic Stress Disorder (PTSD) in children. Research findings estimate that up to one half of children from war-torn countries experience PTSD symptoms. In order to meet the needs of such children, significant adults in their lives need to develop appropriate knowledge and facilitate resilience building programmes(Motta 1995; Price 1995; Mason 1997).

Educators and mental health professionals who serve multicultural communities are faced with the complexities created by resettlement, disruption in support systems and communication barriers. In this context, schools have become the most significant agents of change in shaping future communities. One of the major dilemmas faced by schools, however, is that they have become intervention sites for numerous psycho-social problems affecting school-age children and their families. During an era of declining budgets, school systems have become more cognizant about the need to develop coordinated partnerships and accountable programmes which meet the needs of all involved (Cole 1995; Adelman 1996).

The object of this paper is to document an innovative programme which has brought together expertise in several areas related to children's adjustment needs. By doing so, the International Children's Institute has developed a framework for partnerships which transcends geographical boundaries and advocates for cross-sectional collaboration for the benefit of local communities.

\section{The Building Bridges Programme: The Canadian Site}

The Building Bridges programme was designed, piloted and implemented in schools in Metropolitan Toronto following its inception in 1993. It has been developed by the International Children's Institute, a non-profit humanitarian organization. The Institute has as its mandate the development and implementation of community based programmes in school systems to sup- 
port children's mental health. These programmes are designed to teach coping skills to children (especially those in elementary schools) who are experiencing stress and / or trauma resulting from war, displacement, famine or natural disasters. The Institute's programmes are also designed to enable caregivers to encourage and support children. The Institute brings together teams of parents, psychologists, educators, community health professionals communication professionals and children in order to study and identify the best methods of responding to the needs of the children. The recommendations which emerge from these studies and site assessments within each community are translated into specific programmes. Thus, facilitating communication is the core strategy of the Institute's programmes.

Although initially intended to support the integration of refugee schoolage children, the programme has broadened to encompass all children. Thus, from focusing on children who may have tertiary service needs related to traumatic events, the Building Bridges programme has developed into a primary prevention programme which supports resilience and promotes adaptive coping skills for all children, including immigrant and refugee children, their teachers and parents (Cole and Sroka 1997). By employing a multi-disciplinary, whole school approach the Building Bridges programme has fostered partnerships and school-based activities, which reflect the involvement of each stakeholder group - the children, their parents and the teachers.

This multi-year programme (on average two to three years) begins its work in each site by conducting a needs assessment. Numerous assessment tools have been developed by the International Children's Institute with input from stakeholders and mental health consultants of cross-cultural services. These tools, which include among others community resource audits, needs assessment guides and school profiles, facilitate data gathering and ongoing consultation. It should be highlighted that one of the more authentic tools became the framework for focus groups and panel discussions, which promote the "voices of children" and those who support them both at school and at home. Since communication is a core strategy in all of the International Children's Institute activities, it has led to a process of fluid discovery of needs, gap analysis of services and the shaping of activities in response to the "heard voices of children."

Since the International Children's Institute advocates collective programme ownership, it has documented best practices and developed training and programme implementation guides for ongoing use. These materials have been subjected to modifications and knowledge updates as the programme expands both in Canada and overseas. Examples of materials include: assessment tools; school-based guides for in-service, Principal's guide to the Building Bridges programme; Working with families; Teacher's guide; videos and Caregivers guide to the programme. A website has been established to promote world wide communication about networking and documenting best-practices on behalf of children in stressful situations.

\section{Classroom Based Activities}

As noted earlier, in-class activities were shaped by identified stakeholder needs and by teachers' and consultants' psycho-pedagogical bodies of knowledge. All classroom activities of the Building Bridges programmehave been cross-referenced with the new Ontario Ministry of Education's curriculum guidelines. Thus, these class-based activities are to be viewed as an integral part of curricular objectives. The overall aims of these activities are to promote inclusive educational day to day practices. Therefore, cooperative learning strategies, the promotion of effective communication, the enhancement of proactive social skills, coping skills and positive self-esteem are central goals supported by educators and mental health consultants alike.

The following are highlights of core classroom-based activities, which are documented in detail in the Guides of the International Children's Institute and are used in teacher inservice by schools opting to participate in the Building Bridges programme:

a) Buddy Teams: aims to promote friendships and cultural bridging. It can become a mechanism for social integration and social acceptance by peers;

b) The Change Exchange: aims to identify children's needs, their characteristics of stress and the impact of traumatic events. It can also identify best practices and provide a forum for children to share activities and problemsolving strategies;

c) Games We Like to Play: can further self-confidence through skill development in recreation. Its objectives are to promote positive self-esteem through the mastery of activities, provide a safe way for emotional release of stress and promote friendships;

d) Art is Inside Me: can help with emotional release through self-expression in visual arts. It can also aid in mastery of routine activities and skill development; and

e) Stories in the Classroom: aims to promote story telling and story bookmaking. This framework can help the adjustment of children who have to rebuild assumptions about themselves and their environment. It can put past traumatic experiences into a safer context and can help children develop a positive vision of their future.

\section{Voices of Children, Teachers and Parents: Thematic Research Finding}

Before programmeimplementation and throughout the development of the Building Bridges programme, panel discussions were held with stakeholders to identify goals, needs, coping skills and indicators of success (1994-1997): Children's panel discussions aimed, each year, to explore the nature of entering school; identify behaviors which impact on new students; identify strategies for dealing with stressful situations; explore maintenance of first language and cultural identity; share perceptions of the learning environment; discuss social relations and identify indicators of 
successful adapt- ations and school performance.

Teachers' panel discussions aimed to identify teachers' appraisal of students' needs; document required resources for working with newcomer students; develop a process for collaboration and programme development with the staff of the International Children's Institute and develop mechanisms for home-school partnerships.

Parents' panel discussions, which utilized the services of translators and cultural interpreters, centred around the identification of parental perceptions of children's needs; aimed to explore the value of retaining first language while learning English as a Second Language; assisted parents in better understanding their children's school system; identified multicultural expectations of children; discussed discipline and conflict resolution and identified indicators of success for their school-age children.

Qualitative evaluation data was collected from all stakeholder groups. In addition, quantitative psychometric data was obtained as part of the feasibility study pre and post programme implementation with the children (Fitzgerald 1997; Cole \& Sroka1997). The programme evaluation sample included 147 grade 3 and 4 students in seven programme classes in four schools. As part of the study, 77 students in four additional classes in the same schools acted as control groups. The four participating schools are located in different neighbourhoods in Toronto and represent the diverse demographic makeup of the student population. For example, in one of the elementary schools, 60 percent of the student population comprised children born outside Canada.

The psychometric battery was chosen to reflect norm-referenced and culture-fair measures which have been in use with heterogeneous student populations in Canada and the United States (Fitzgerald 1997). Data were collected through child self-report questionnaires read out to students in order to minimize the impact of English as a
Second Language reading proficiency. Pre-post data gathering took place in a six month interval period.

Key findings from the psychometric study highlight that: a) children in participating classes reported having more close friends by the end of the programmeimplementation year than their control counterparts; $b$ ) by theend of the school year, children who took part in the Building Bridges programme reported a wider range of people with whom they could communicate about their needs or problems than their counterparts in control classes. Taken together, these findings indicate that children in participating programmes demonstrated better ability to develop adaptive communication skills and better social relationships, all of which comprise key indicators of mental health.

The qualitative data were consistent with the quantitative study findings. Indeed, early in the needs identification phase, children identified language development, communication and orientation as key priorities. However, as their skills in English as a Second Language developed, other thematic issues were identified in subsequent panel discussions. Those included social needs such as friendships, welcoming other students and conflict resolution strategies. The children gave examples to support their opinions and by doing so, demonstrated an increased awareness of the process of integration in their local schools.

Parents and teacher discussion panels identified a range of needs at the early part of the programme. At that stage, they noted immediate needs including orientation related information, knowledge about resources for newcomers and avenues for communication between teachers and parents. As Building Bridges programmeimplementation progressed, expressed themes came to encompass issues concerning children's social integration, academic outcomes, self-esteem and maintenance of home language and cultural heritage. Since both parents and teachers aimed at strengthening home-school ties, discussion meetings shifted from problem and needs identification into a problem-solving phase. By doing so, they began to share knowledge and examples which aided the integration of children in adaptive and developmentally appropriate ways.

In summary, the Building Bridges programme documented the value of cross-sectional collaboration at the school and community level. This multi-year partnership between parents, children, school and International Children's Institute staff aided the overall improved adjustment of children. Findings through discussions, student class work, self-report questionnaires and observations demonstrated the value of combining school and community resources to support newcomer children.

Sinceboth the process of programme development and programme implementation have been documented in user guides, it is likely to facilitate easy dissemination of knowledge to new Building Bridges sites. The International Children's Institute is currently consulting with school boards about programme expansion and development to meet local needs in concert with curriculum guidelines.

\section{Building Bridges Overseas}

... [A]fter five minutes we heard three more bombs. I was afraid. I could feel my blood freeze. It was too dangerous to wait for my parents to come back to the apartment, so we went to the basement... the next days of the bombing were terrible..." (written by T., a 12 year old new Canadian student)

This child's story represents many voices of traumatized children who have suffered displacement following the aftermath of war and its devastating impact. These types of experiences can be long lasting both for individuals and the communities as a whole. They require holistic interventions that move individuals and groups from a state of helplessness to a path of rebuilding of the self despite adversity (Cole 1996; 1998; Williams \& Berry 1991; Jensen \& Shaw 1993). The Building Bridges Programme has been implemented in recent years in Croatia, Bosnia and 
Herzegovina and in Albania. The Institute is currently consulting in Kosovo. By adopting a whole community approach, similar to the framework documented in Canada, International Children's Institute teams have been able to keepcore programmegoals while adjusting to local needs.

In Croatia, for example, the International Children's Institute has implemented the Building Bridges programme since the early 1990 s by fostering cross-sectional links to support educational programmes. As documented in the Canadian programme, discussion and focus groups with children, parents, teachers, mental health professionals and community care givers have resulted in the identification of the psycho-social and educational needs of children suffering from the effects of war. In addition to the identification of needs, the programme also documented coping strategies, knowledge and skills which represent the stakeholders effective practices during the phase of rebuilding the social fabric of the communities. A conference including participants from 13 schools and stakeholders provided a platform for exchange of experiences and application of Building Bridges solutions to common local problems.

In Bosnia and Herzegovina International Children's Institute teams conducted site visits as part of the needs assessment. A gap analysis which was coordinated with local professionals, NGOs and community representatives shaped the Building Bridges programme framework and interventions. Again, as published in Canada, a series of guidebooks were developed in order to assist professionals with future programme planning. A community conference held in 1999 provided a mechanism for sharing knowledge, learning about programme opportunities and displaying children's work in the process of rebuilding their trust in themselves and in those who support them towards a stable future.

The International Children's Institute is currently involved in developing psycho-social programmes for Kosovo refugees in Albania. Site assessments in refugee camps in and around Tirana haveled to a better understanding of the living conditions and the availability of local resources. This knowledge links the assessment outcome knowledge with the development of local psychosocial programmes. For example, over 40 site visits and meetings were held with Albanian government officials, local and international humanitarian organizations, health centres, schools and municipal officials. This type of assessment process has enhanced the knowledge of those involved in providing aid and is likely to shape more authentic interventions for populations exposed to physical and psychological brutalities.

The framework and nature of the Building Bridges programme for refugees is presently being documented in a guidebook and on a video programme designed for psychosocial interventions in refugee camps. It will include the following:

a) Orientation and pre-deployment training. This training based on a "train-the-trainer" model, will be coordinated with local staff and will aim to train teachers, among others, to learn skills involved in providing psychological first aid;

b) Recreational and out of school activities. These are likely to support children's social skills and communications through organized activities modified from the Building Bridges programme. Summer programmes are akey part of this phase; and

c) Long-term programmes. These programmes are embedded in the academic year and reinforce curriculum objectives while supporting children's competence and confidence building. Whole school activities and parents' support groups will likely result in skill development towards resettlement.

\section{Conclusion}

The transformation of communities in Canada and overseas requires complementary programmes which emphasize a team approach to needs identification, design, implementation, monitoring and assessed outcomes (Cole 1996). Nevertheless, the complexities associated with funding for both NGOs and for professional services in existing systems often results in advocacy for needs identification and to a lesser extent in the documentation of sustained long-term programmes (Herman 1994; Hicks Lalonde \& Pepler 1993; UNHCR 1995). The Building Bridges programme has systematically documented a framework which aims to overcome difficulties associated with over reliance on traditional services for traumatized children and their families.

Both overseas and in Canada the International Children's Institute has combined "bottom-up" with "topdown" knowledge and partnerships which have allowed for a more timely design and implementation of locally modified programmes. Identifying key people in all local sectors, has led to stronger communication patterns within a range of initiatives and a model which has linked primary, secondary and tertiary prevention services (Cole 1998). To date, qualitative and quantitative studies of the Building Bridges programme support this framework (Cole \& Sroka, 1997). In line with the trend toward increased accountability in government, health, education and NGOs, there seems tobe a growing need to address outcome-based measures for programmes. Major change in service orientation will consequently require modifications in thinking, planning, advocacy and utilization of resources.

\section{References}

Adelman,H.S. 1996. Restructuring Education Support Services and Integrating Community Resources: Beyond the Full Service School Model. School Psychology Review, $25,4,431-445$.

Ajdukovic, M., and Ajdukovic, D. 1993. Psychological Well-Being of RefugeeChildren. Child Abuse and Neglect, 17, 843-854.

Beiser, M., Dion, R., Gotowiec, A.J. and Huyman, I.1995. Immigrant and Refugee Children in Canada. Canadian Journal of Psychiatry, 40, 2, 67-72.

Cole, E. 1995. Responding to School Violence. Canadian Journal of School Psychology, $11,2,103-116$.

Cole, E. 1996. Immigrant and Refugee Children and Families: Supporting a New Road Travelled. In M., Luther, E., Cole, and P., Gamlin. Dynamic Assessment for 
Instruction: From Theory to Application Toronto: Captus University Press.

Cole, E. 1998. Immigrant and Refugee Children: Challenges and Opportunities for Education and Mental Health Services. Canadian Journal of School Psychology, 14, 1, 36-50.

Cole, E. and Sroka, I. 1997. Long Term Trends of the Building Bridges Programme: A Thematic Summary. Montreal: The International Children's Institute.

Fitzgerald, J. 1997. An Assessment of the Feasibility of Evaluating the Building Bridges Programme. Montreal: The International Children's Institute.

Herman, R.D. and Associates 1994. The Jossey-Bass Handbook of Nonprofit Leadership and Management. San Francisco: Jossey-Bass Publishers.

Hicks, R., Lalonde, R.N., and Pepler, D. 1993. Psychosocial Considerations in the Mental Health of Immigrant and Refugee Children. Canadian Journal of Community Mental Health, 12, 2, 718-728.

Jensen, P. and Shaw, J. 1993. Children As Victims of War: Current Knowledge and Future Research Needs. Journal of American Child and Adolescent Psychiatry, 32, 4, 697-708.

Mason, S.M. 1997. Cross-cultural and Multiethnic Assessment of Trauma. InJ.P. Wilson and T.M. Keane (Eds.), Assessing Psychological Trauma and PTSD. New York: The Guildford Press.

Motta, R.W. 1995. Childhood Post-Traumatic Stress and the Schools. Canadian Journal of School Psychology, 11, 1, 65-78.

Price, K. (Ed). 1995. Community Support for Survivors of Torture: A Manual. Toronto: Canadian Centre for Victims of Torture.

The International Children's Institute. 1995. Building Bridges: Report on theChildren's Panel Discussions. Montreal.

The International Children's Institute. 1998. Building Bridges Programme Guides. Montreal.

United Nations High Commissioner for Refugees. 1994. Refugee Children. Geneva: UNHCR

United Nations High Commissioner for Refugees. 1995. The State of the World's Refugees: In Search of Solutions. New York: Oxford University Press.

Vargas, C.M. 1999. Cultural Interpretation for Refugee Children: The Multicultural Liason Programme, Ottawa, Canada. Refuge, 18, 2, 32-42.

Williams, C.L. and Berry, J.W. 1991. Primary Prevention of Acculturative Stress among Refugees. American Psychologist, 46, 6, 632-641. a

\section{Back Issues of Refuge, Canada's Periodical on Refugees}

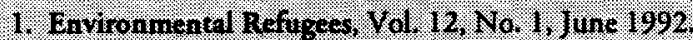

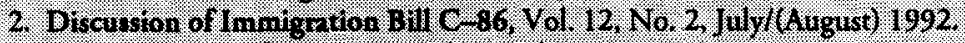

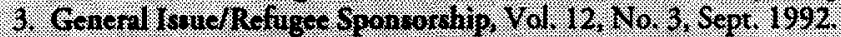



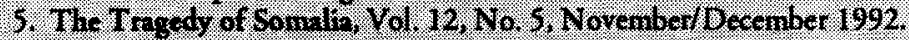

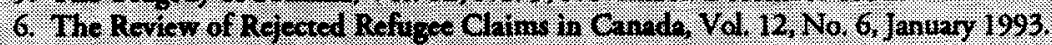

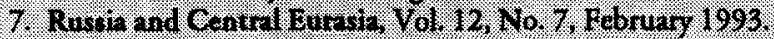

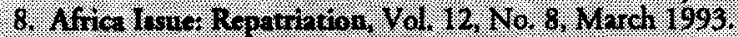

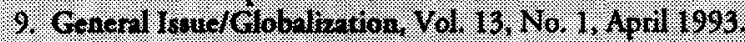

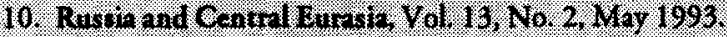

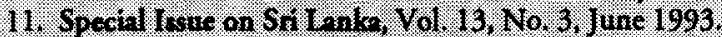

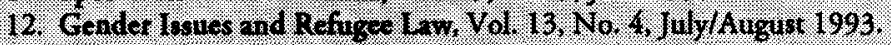

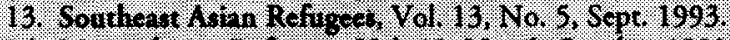

14. Mozmbican Refuzen, Vol 13, No.6, October 1993.

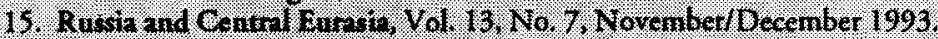

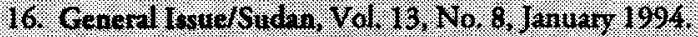

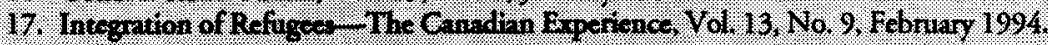

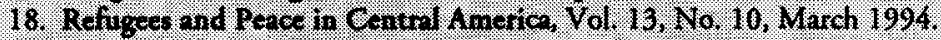

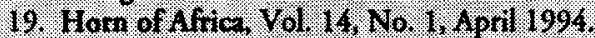

20. The Rinsitan Federetern, Vol, 14, No. 2, May 1994 .

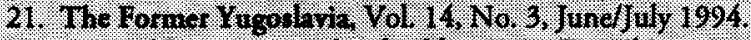

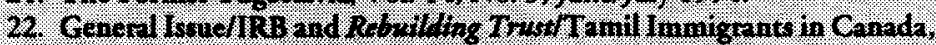
Vol. 14, No. 4, AugrardSapramber 1994

23. R.randan Crisis. Vol. 14. No. 5. October 1994.

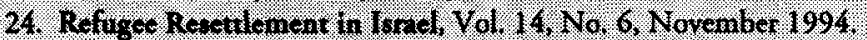

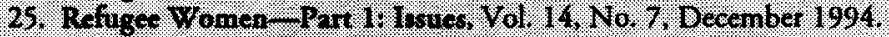

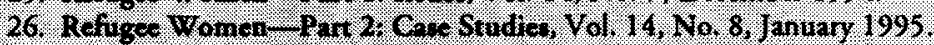

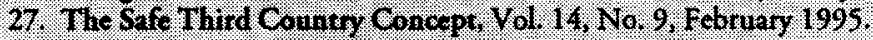

28. Special Turee on Mhedinge. Yol. 14, No. I0, Mardh 1995.

29. Reformulation of thrtermational Refuged I 2 w, Yol. 15, No. 1,1996

30. Entiromment, Devolopment and Refigges, Vol, 15 , No. 2, 1996.

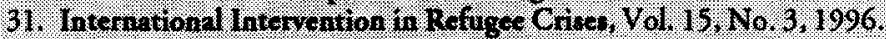

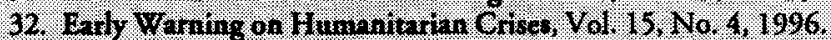

33. Child Refugece, Yol. 15. No. 5. 1996.

34. Alobd Settlement Services, Vol. 15 , Na. 6, 1997 .

36. Eari, Woming and Ealy Respone, Vol. 16. No. 1, May 1997

36. Uprooting and Consquicicon, Val. 16, No. 2, June $199 \%$

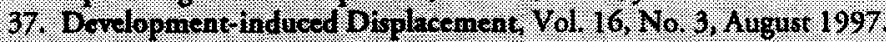


Ocrober. 1997 .

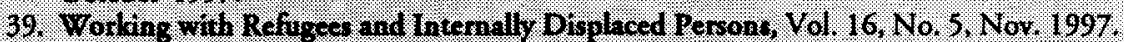

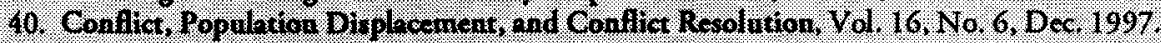

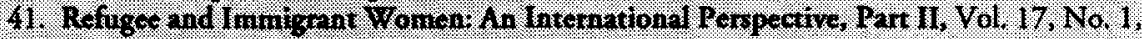
Februtin 1998.

42. Muman Righte ond Refiges Morements in the Newly Independent States of the Formor Sovier Union, Vol 17, No. 2 , A pril 1998.

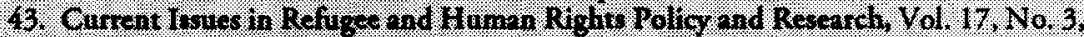
August 1998.

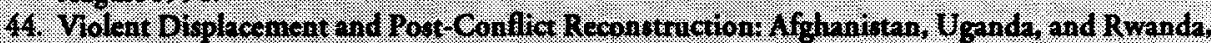
Vol. 17. No. 4. Octeber 1998.

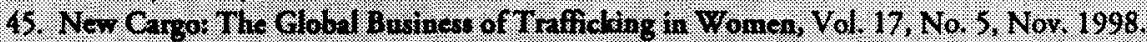

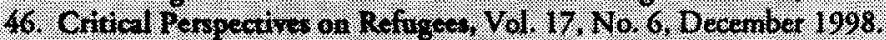

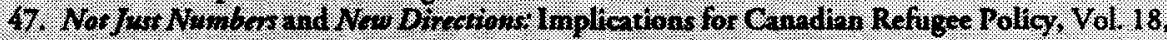
No. 1. I Rebruar, 1999.

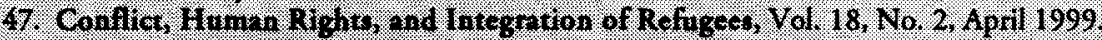

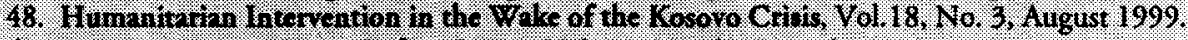

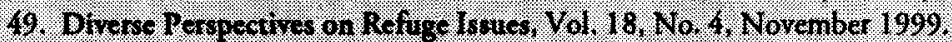

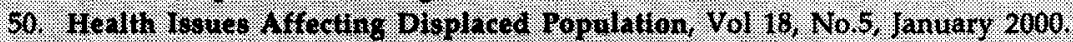

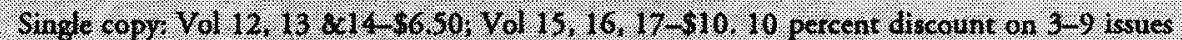
(copies) 20 percent discount on 10 issurs (copies) or nore. Special discounts are avallable for

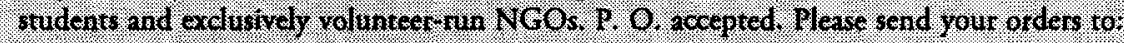

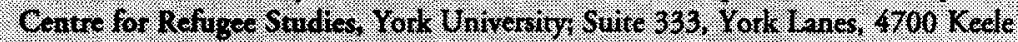

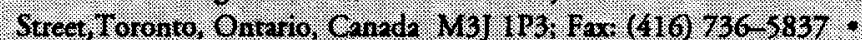

